\title{
The Concept of Engineering $\mathcal{E}$ Humanities: A new discipline
}

\author{
Haoxuan Yu ${ }^{1}$, Shuai Li ${ }^{1, *}$ and Xinmin Wang ${ }^{1}$ \\ ${ }^{1}$ School of Resources and Safety Engineering, Central South University, Changsha, Hunan Province, China \\ * Correspondence: $15200826420 @ 163 . c o m$
}

\begin{abstract}
In our long-term engineering practice, we have found that it is often not enough to use only engineering knowledge to solve the practical problems in the engineering. Therefore, we believe that in the education of engineering students, we should not only pay attention to the teaching of engineering knowledge, but also pay attention to the application of knowledge of Humanities in the engineering, for the students. In this two-part concept paper, we put forward the concept of a new discipline, that is, Engineering \& Humanities, which we will carry forward in future. And this concept paper serves just as a guide to the Tossing out a brick to get a jade gem with the implications for the development of the engineering education.
\end{abstract}

Keywords: Engineering; Humanities; Discipline.

\section{Introduction}

Actually, Engineering and Humanities are two disciplines with many connections.

In 2019, P. Duffaut and J. Larouzee ${ }^{[1]}$ analyzed the collapse of the arch dam in southeastern France in 1959, and they believed that human activity was closely related to the engineering. In the same year 2019, C. Weidner, R. Braidotti and G. Klumbyte ${ }^{[2]}$ believed that in this new era, the humanities must have the necessary "dialogue" with the natural sciences, especially the engineering science. In fact, as early as in 2006, R. R. Ernst ${ }^{[3]}$ have proposed that there are intersections between Engineering and Humanities, and then in 2007, J. A. Stieb ${ }^{[4]}$ proposed that both Engineering and Humanities have a common feature, that is, "optimizing the human beings".

Specially in 2014, the scholars A. Chong, L. Wilkinson and D. Tihanyi ${ }^{[5]}$ explained intersections between Engineering and Humanities further and started the practice of a new teaching method:

- They believed that a broad-based general education is essential to the critical reading and thinking abilities of engineering students.

- They promoted the integration of science and engineering themes with human activities and teaching methods, and encouraged students majoring in engineering to participate freely.

After the practice, they draw some conclusions through teachers' teaching experience and students' feedback:

- The classroom atmosphere created by a group of engineering students who take part in traditional humanities education is unique and of high value. Their subject and professional knowledge make the curriculum content have an important point of view.

- Students who study the Engineering will benefit and learn about the relevance of Engineering to Humanities.

As a result, for pedagogy, their research is a very effective practice, which proves the importance of Humanities to the students who study the Engineering. And from the point of view of Engineering, Humanities also have a great influence on Engineering, such as the coexistence of people in the engineering practice or engineering projects, and the harmony between man and nature.

\section{Definition}

In the practical engineering, some problems of Humanities will inevitably be encountered, such as the sustainable development of resources or the protection of the environment, and even the relationship between people in the engineering projects. Therefore, in the education of college students, it is far from enough to teach them how to solve the problems in the practical engineering.

This part mainly aims at the education of college students, puts forward a new discipline, that is, Engineering $\mathcal{E}$ Humanities, and we have defined it: 
- Engineering $\mathcal{E}$ Humanities is a discipline which studies the relationship between people, and the relationship between the human and the nature in the engineering.

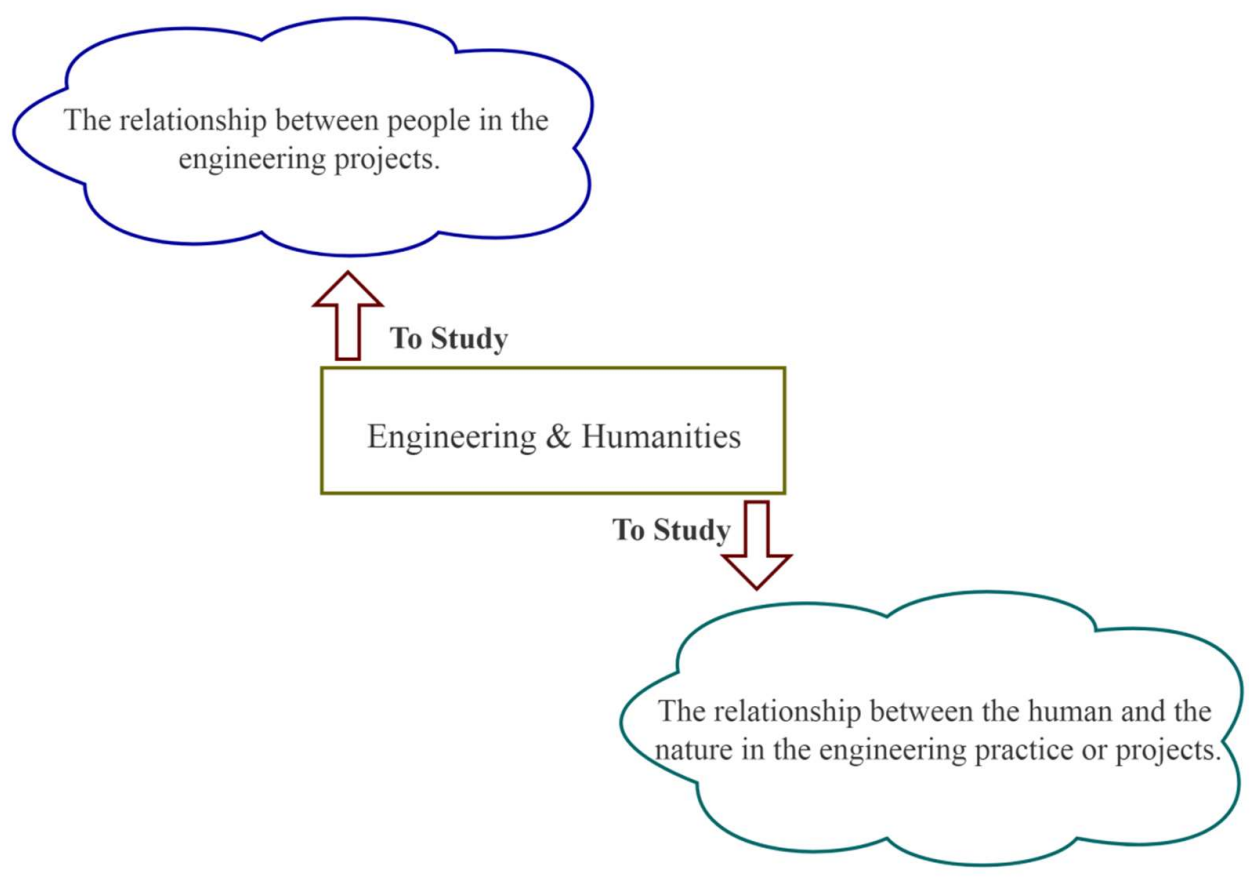

Figure 1. Engineering \& Humanities.

\subsection{The relationship between people}

In the engineering, the relationship between people is very important, so it is also a must for students to learn how to deal with the interpersonal relationships. The relationships between people in the Engineering \& Humanities include:

- Relationship between workers and workers.

- Relationship between workers and foreman.

- Relationship between worker, foreman and engineers.

- Relationship between staff(worker, foreman and engineers) and managers(boss).

- Relationship between managers and managers. 


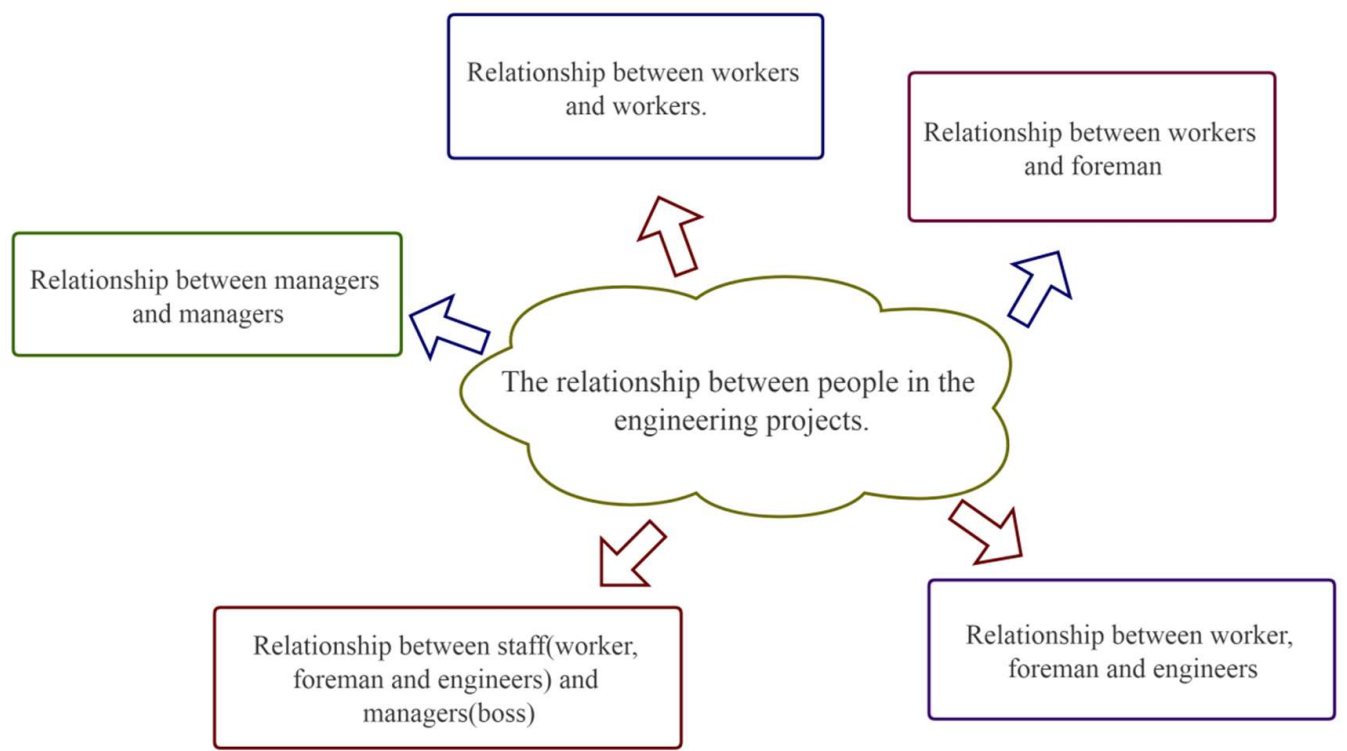

Figure 2. The relationship between people in the engineering.

For students, in this part, what they need to learn is:

- If you are a lower class employee, please handle your relationship with other employees and your upper class.

- If you are a manager, handle your relationship with the lower level, the same level and the upper level.

And I would like to take China's engineering practice as an funny example to more vividly explain the above:

- If you are a lower class employee, please learn how to play card games in harmony with other employees to spend your free time and learn how to how to drink with the upper leaders and please them.

- If you are a manager, please learn how to reward your subordinates for their positive work attitudes and learn how to join your peers and please your upper leaders.

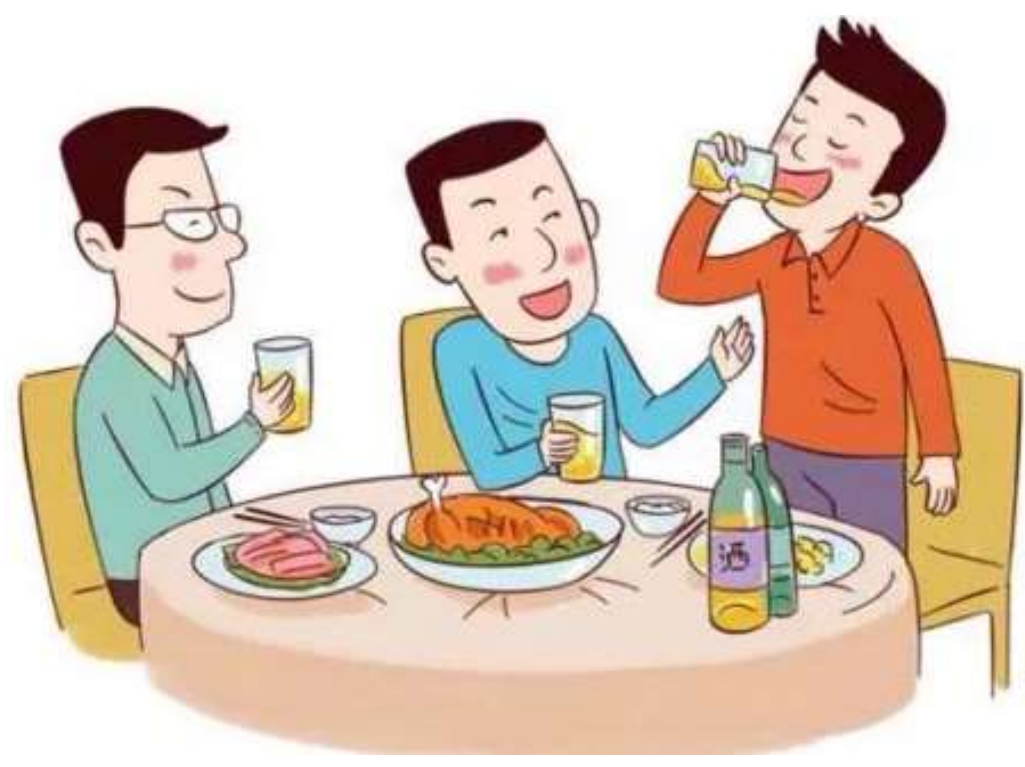

Figure 3. Drink with your the upper leaders.

Although this is only an interesting example, it also shows the importance of dealing with interpersonal relationships in engineering practice or projects. 


\subsection{The relationship between the human and the nature}

Harmony between the human and the nature has been the advocate and call of people since ancient times, up to now, There are still scholars such as A. Zingraff-Hamed et al[6] and Y. Wang et al[7] still advocating the idea of harmony between man and nature.

The same in the engineering, we need to take into account the environmental impact of engineering, such as pollution and damage. Therefore, in the process of engineering projects, we must eliminate these negative effects on nature, as the requirement of Engineering \& Humanities.

The factors need considering in the relationships between the human and the nature in the Engineering $\mathcal{E}$ Humanities include:

- Conservation of nature, such as pollution control, afforestation and other measures.

- Rational exploitation of nature, that is, sustainability of natural exploitation.

- Rational use of natural resources, not excessive exploitation of natural resources.

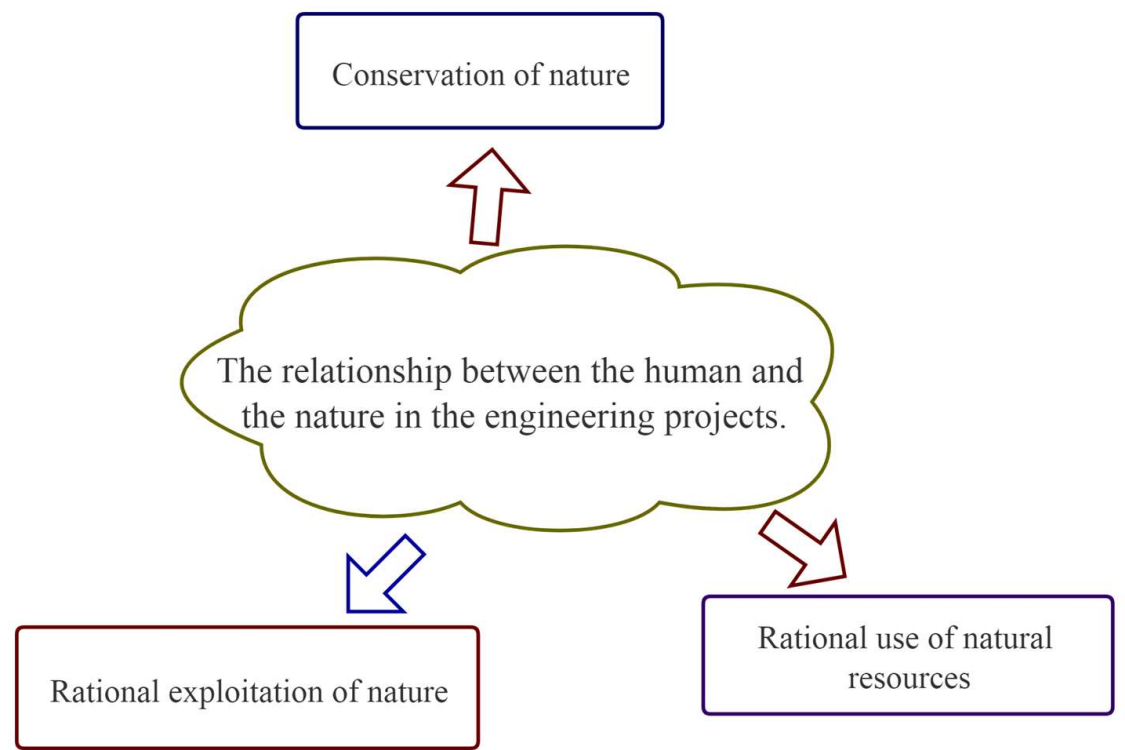

Figure 4. The relationship between the human and the nature.

For students, in this part, what they need to learn is:

- Learn to assess the potential damage to nature before the project begins.

- Learn to deal with the damage to nature in the engineering projects.

- Sustain the sustainable use of natural resources.

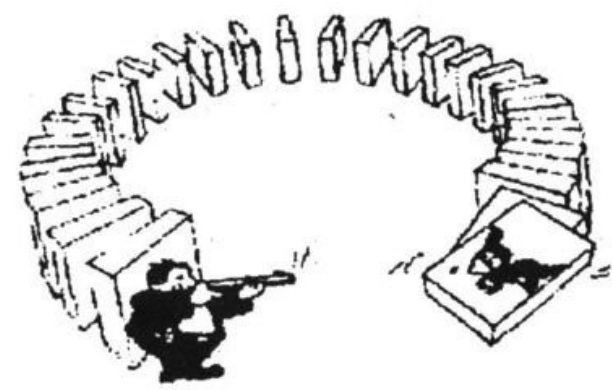

Figure 5. The relationship between the human and the nature. 


\subsection{The future work}

In the following research and practice, we will try to pilot the discipline in the college study, and gradually improve it, the purpose of us is to improve the comprehensive quality and humanistic literacy of the students who study the engineering.

Finally, the authors claim that the concept paper serves just as a guide to the Tossing out a brick to get a jade gem, has a few implications for the development and the future of the engineering education, and it is hoped that more and more scholars will be interested and engage in the research of this field.

\section{Funding:}

The authors thank the financial supports from the National Natural Science Foundation of China (51804337).

\section{Authors' Contribution:}

Haoxuan Yu- Conceptualization / Writing - original draft / Writing - review \& editing.

Shuai Li- Resources / Supervision / Software / Validation.

Xinmin Wang- Project administration.

\section{Acknowledgment:}

Special thanks to the editors for long-term guidance to authors.

The authors thank the financial supports from the National Natural Science Foundation of China (51804337).

\section{Conflicts of Interest:}

The authors declare no conflict of interest.

\section{References}

1. P. Duffaut and J. Larouzee, "Geology, engineering \& humanities; 3 sciences behind the Malpasset Dam failure (France, Dec. 2 , 1959)," Quarterly Journal of Engineering Geology and Hydrogeology, vol. 52, (4), pp. 445-458, 2019.

2. C. Weidner, R. Braidotti and G. Klumbyte, "The Emergent Environmental Humanities: Engineering the Social Imaginary," Connotations (Münster in Westfalen, Germany), vol. 28, pp. 1-25, 2019.

3. R. R. Ernst, "Science, engineering, and humanity. Our contribution to the future," IEEE Engineering in Medicine and Biology Magazine, vol. 25, (3), pp. 18-19, 2006.

4. J. A. Stieb, "On "Bettering Humanity" in Science and Engineering Education," Science and Engineering Ethics, vol. 13, (2), pp. 265-273, 2007.

5. A. Chong, L. Wilkinson and D. Tihanyi, "Intersections of humanities and engineering: Experiments in engineering specific humanities electives and pedagogies," in 2014, .

6. A. Zingraff-Hamed et al, "Human-River Encounter Sites: Looking for Harmony between Humans and Nature in Cities," Sustainability (Basel, Switzerland), vol. 13, (5), pp. 2864, 2021.

7. Y. Wang et al, "Ecological Conservation Redline will promote harmony between humans and nature in the future," Ambio, vol. 50, (3), pp. 726-727, 2021. 